DOI 10.37882/2223-2982.2022.01.30

\title{
МЕТОДОЛОГИЧЕСКИЕ ПОДХОДЫ К ФОРМИРОВАНИЮ ИНТЕРАКТИВНЫХ КОМПЕТЕНЦИЙ БУДУЩИХ УЧИТЕЛЕЙ ФИЗИЧЕСКОЙ КУЛЬТУРЫ
}

\section{METHODOLOGICAL APPROACHES TO THE FORMATION OF INTERACTIVE COMPETENCIES OF FUTURE PHYSICAL EDUCATION TEACHERS}

A. Surkov

L. Karseka

R. Gezha

Summary: The conducted research in the article allowed us to obtain a number of important theoretical results containing the solution of the scientific problem of the formation of interactive competence of future physical education teachers in the educational process of higher education institutions. Based on the analysis and generalization of scientific sources on the research problem, the content of the basic concepts of research was clarified and described: "interaction", "interaction", "future teacher of physical culture", which contributed to the understanding of the concept of "interactive competence of future teachers of physical culture" in the educational process of universities. Methodological approaches systemic, personal-activity, competence-based, humanistic, communicative, and facilitative - have been identified and have provided philosophical and pedagogical foundations that have allowed for a more detailed analysis of the research problem - a characteristic of the activity of a physical education teacher.

Keywords: learning principles, approaches, competencies, physical culture, interaction, interaction, facilitation.
Сурков Александр Михайлович

к.п.н., дочент, ФГБОУ ВО «Московская государственная академия ветеринарной медицины и биотехнологии имени К.И. Скрябина»

surkov.1954@bk.ru

Карсека Лина Сергеевна

cm. nреподаватель, ФГБОУ ВО «Московская государственная академия ветеринарной медицины и биотехнологии имени К.И. Скрябина»

kls-lina@mail.ru

Гежа Роман Валерьевич преподаватель, ФГБОУ ВО «Московская государственная академия ветеринарной медицины и биотехнологии имени К.И. Скрябина» gezha.r@yandex.ru

Аннотация: Проведенное исследование в статье позволило получить ряд важных теоретических результатов, содержащих решение научной задачи формирования интерактивной компетентности будущих учителей физической культуры в образовательном процессе учреждений высшего образования. На основе анализа и обобщения научных источников по проблеме исследования было выяснено и описано содержание базовых понятий исследование: «интеракция», «взаимодействие», «будущий учитель физической культуры», что способствовало пониманию понятия «интерактивная компетентность будущих учителей физической культуры» в образовательном процессе вузов. Определены методологические подходы - системный, личностно-деятельностный, компетентностный, гуманистический, коммуникативный, фасилитативный - обеспечили философско-педагогические устои, которые позволили осуществить более детальный анализ проблемы исследования - характеристику деятельности учителя физической культуры.

Ключевые слова: принципы обучения, подходы, компетенции, физическая культура, интеракция, взаимодействие, фасилитация.

Ко второй группе понятий, характеризующих особенности обозначенной компетентности будущих учителей именно физической культуры, отнесены дефиниции: «физическое воспитание», «будущий учитель физической культуры».

Итак, к первой группе мы отнесли базовые понятия «интеракция», «взаимодействие».

Из справочно-энциклопедических источников мы выяснили, что слово «интеракция» или «взаимодействие» происходит от латинского, французского и английского "interaction", составляющими элементами которого являются префикс "inter", что означает «взаимное», «между», «посреди»; и корень "action" - действие, деятельность. 
Анализ научных работ свидетельствует, что в отечественных и зарубежных подходах термин «интеракция» употреблено в нескольких контекстах:

1. характеристика деятельности, в которой участвуют двое или более субъектов общения (В.К. Бальсевич) [9];

2. обмен мнениями или идеями в рамках сотрудничества (А.Б. Евтин, А.Н. Гусев) [16];

3. обмен мнениями, идеями или чувствами двух или более субъектов в ходе взаимодействия, результатом которого является положительное влияние на реципиентов взаимодействия (Х. Браун) [20];

4. форма активизации работы учащихся с помощью учебного общение в рамках групповой работы (П. Ур) [29];

5. форма общения, учитывающая речевую деятельность, взаимодействие, результатом чего является формирование умений общения реципиентов при необходимых условиях и потребностях (Лео ван Лаер) [30].

Взаимодействие имеет разнообразие функций, выделенных Л.Д. Столяренко. Среди них автор определяет:

1. конструктивную - проявляется при объяснении и обсуждении содержания материала и его практической значимости;

2. организационную - организация совместной учебной деятельности;

3. коммуникативно-стимулирующую - организация взаимопомощи с целью педагогического сотрудничества, использование разнообразных форм учебно-познавательной деятельности;

4. демонстративно-информационную - показ связи учебного предмета с производством;

5. эмоционально-корректирующую - доверительное, чувствительное общение, взаимопонимание, смена видов учебной деятельности;

6. контрольно-оценочную - организация взаимоконтроля, совместное подведение итогов, оценка, самооценка [18, с. 390-391].

Относительно структуры взаимодействия С.Н. Литвиненко выделяет следующие элементы:

1. пребывание участников взаимодействия в едином пространстве и времени, установление непосредственного межличностного контакта;

2. определение цели и ожидаемых результатов совместной деятельности;

3. планирование, контроль, коррекция общих действий и их координирования;

4. равное распределение общего труда между всеми участниками;

5. установление субъект-субъектных взаимоотношений [15].

Однако, по мнению многих международных иссле- дователей, для эффективного взаимодействия должна быть интенсивная межсубъектная коммуникация ее участников, изменение и разнообразие ее видов, форм и приемов, целенаправленная рефлексия участников коммуникации $[21 ; 22 ; 24 ; 25 ; 30]$.

Американская ученая Мэри Э. Диез (Mary E. Diez) выразила следующие мысли об эффективном взаимодействии через общение:

1. процесс взаимодействия помогает учащимся расширить спектр стилей поведения;

2. развитие умений взаимодействия происходит благодаря структурному анализу, целеполаганию, практики и отклика (обратной связи) на выполняемые действия;

3. умение взаимодействия накапливаются в процессе обучения и во внешкольной жизни учащихся;

4. умения взаимодействия взаимосвязаны с коммуникативными, когнитивными и аналитическими умениями, умением решения проблемных вопросов;

5. накопление умений взаимодействия происходит в контекстном обучении через рефлексию собственных действий и уровень достигнутых результатов [23].

Оригинальной является концепция Кенета Д. Мура по эффективному взаимодействию через общение, отраженная в «системе интерактивного анализа», которая была разработана Н.А. Фландерсом, Э.Дж. Амидолом, И.Дж. Каспером в 1985 году (The Flanders Interaction Analysis System или «Фландеровская система категорий взаимодействия» по Б. Бархаеву) [26]. Вводя эту систему, можно изучить типы общения через вербальное поведение на занятии. Преподаватель может сформировать представление о общее поведение студентов, о динамике развития их взаимоотношений и психологическую атмосферу в группе. Система Н.А. Фландерса, например, позволяет оценить уровень речевого взаимодействия по десяти категориям:

1. диагностика чувств - распознавание положительных или отрицательных чувств учеников в неагрессивной, деликатной манере речи;

2. одобрение или ободрение - одобрение или ободрение учеников с целью снижения напряжения и преодоления трудностей на занятии;

3. анализ идей учащихся - разъяснение и развитие идей, предложенных учениками;

4. постановка вопросов - постановка вопросов по содержанию занятия или характера деятельности учащихся;

5. речь - сообщение новых фактов относительно содержания учебного процесса;

6. предоставление указаний-формулирование инструкций или советов учащимся для улучшенного выполнения учебных задач; 
7. критика действий или подтверждение собственного авторитета - объяснение учителем, почему существующее поведение не является приемлемым, формулировка ряда ожиданий относительно деятельности учащихся;

8. разговор ученика как ответ учителю - предоставление ответов на вопросы учителя как средство анализа качества и глубины усвоенных знаний и умений;

9. разговор ученика по собственной инициативе проведение дискуссии между учениками; учитель наблюдает, анализирует и диагностирует уровень сформированности психологических, коммуникативных, интерактивных умений;

10. тишина или смущение - наблюдение за процессом интеракции учащихся; прогнозирование вероятных трудностей; анализ событий, которые усложнили ли остановили взаимодействие между учениками и смутили их.

С внедрением образовательных инноваций в образовательный процесс через субъекты взаимодействия возможно достижение следующих целей:

1. улучшение мотивационной направленности ее участников;

2. формирование нового типа отношений между субъектами взаимодействия (партнерство, взаимоуважение, двустороннее деловое общение);

3. создание комфортных условий для принятия собственных решений, обсуждение и воплощение коллективных (групповых, командных) решений, от которых будет зависеть качество, успешность и эффективность выполнения заданий учебного процесса [1].

Таким образом, проведенный анализ делает возможным определение понятия «взаимодействие» или «интеракция». На наш взгляд, содержание ранее употребляемого и общепринятого понятия «взаимодействие» в настоящем понимании отражает содержание современного международного понятия «интеракция», что постепенно выжимает предыдущий термин из научной литературы.

В нашем исследовании «взаимодействие» или «интеракция» трактуется как активизация работы будущих учителей в парной, групповой деятельности, это умение устанавливать межличностный контакт, принимать общие решения, умения равноправного участия в совместной деятельности, накопления опыта толерантного, уважительного отношения к различным взглядам и мнениям в ходе выполнения поставленных учебных заданий.

По мнению различных ученых, общими признаками взаимодействия в образовательном процессе будущих учителей физической культуры являются:

1. продуктивный характер коллективной деятельности на уроках физической культуры (наличие целеустремленности, осознанности, опосредованности, процессуальности и т.п.) [5];

2. активизация работы участников образовательного процесса во время проведения занятий физической культурой (положительное отношение к деятельности и ее результатов, инициативность, ответственность) [6];

3. интеграция свойств личностно-ориентированного (обмен умениями, навыками, опытом) и личностно-делительного (процесс получения будущими учителями знаний, умений и навыков, компетенций в общей деятельности) подхода к обучению [12];

4. ориентация на здоровьесбережение (развитие физических качеств и двигательных способностей, формирование технико-тактических умений и навыков соответственно школьной программе по видам спорта) и интеллектуальное развитие личности (развитие речевых, когнитивных, эмпатических умений, формирование духовных, культурных и морально-этических ценностей) [13];

5. коллективный труд в рамках парной или групповой деятельности студентов на занятиях физической культурой (совместное выполнение физических упражнений и двигательных задач и тому подобное) [14].

Важной основой для выяснения основ взаимодействия является определение научных принципов субъект-субъектного взаимодействия, к которым можно отнести следующие принципы: взаимообучение, учебной автономии, активизации учебной деятельности, адаптации и гибкости, социализации, культуросообразности, профессионального развития, обратной связи, системности.

Принцип взаимообучения предопределяет создание и соответствие основам взаимодействия (благоприятная психологическая атмосфера, позитивная мотивация к взаимодействия, надлежащая интерактивная среда), при которых студенты овладевают новыми знаниями, умениями и навыками, развивают свои способности и качества, используют их в ходе выполнения заданий интерактивного характера (С.Н. Литвиненко [15]).

Мы считаем этот принцип самым важным при обучении спортивным движениям, в особенности при формировании техники движений (работа в парах, тройках, малых группах).

Применение принципа взаимообучения в процессе изучения студентами предметов профессиональноориентированного цикла позволяет студентам быть 
главными субъектами взаимодействия и участвовать в структурировании учебного материала по спортивнопедагогическим дисциплинам; организовывать и поддерживать межсубъектное общение и сотрудничество; осуществлять интерактивное обучение, приоритетом которого является формирование и развитие различных компетентностей студента. Считаем, что принцип взаимообучения учитывает требования педагогики равенства, способствует эффективной реализации образовательных основ «равный - равному», а также способствует обучению через действие (обучение действием).

Принцип учебной автономии делает возможным самостоятельное приобретение новых знаний и умений; расширение учебного опыта; определение комфортных методов и механизмов интерактивного обучения: работа в паре, в группе, в команде (Д. Браун [20], Л. Ван Лаер [30]).

В условиях применения принципа учебной автономии преподаватель может создавать интерактивные задания, выполнение которых оптимизирует дальнейшее развитие сформированных двигательных компетентностей, психических, психологических, индивидуальных способностей (гибкость, мобильность, адаптивность, умение работать и взаимодействовать с другими, умение организовать собственный учебный и свободное время, множественные интеллектуальные способности и тому подобное). Этот принцип отвечает требованиям непрерывного самостоятельного профессионального образования.

Принцип активизации индивидуальной деятельности обязывает строго учитывать возрастные особенности, пол, уровень подготовленности, индивидуальные различия в физических и психических способностях личности. Он способствует целенаправленному выполнению интерактивных заданий с целью усвоения учебного материала в группе, в паре, самостоятельно; участия в обсуждении плана действий по достижению обозначенных целей. Это может происходить на семинарских или практических занятиях, при изучении теоретических курсов, принятии совместных решений; в дискуссии с проблемных вопросов; в устном и письменном взаимодействии; при сфокусированном (активном) слушании; при подготовке и выступлении с докладом; взаимодействии с слушателями презентации или участниками «мастер-класса».

Принцип активизации индивидуальной деятельности мотивирует участие студентов с более высоким развитием физических и координационных качеств, с более высоким уровнем технической подготовленности к интерактивному взаимодействию при выполнении физических упражнений, а студентов с множественными интеллектуальными способностями к интерактивному общению. Этот принцип реализуется на принципах гуманистического, личностно-ориентированного, коммуникативного и фасилитативного подходов к обучению.

Принцип адаптации и гибкости (П.П. Николаев, И.В. Николаева [7], Е.А. Челнокова, Н.Ф. Агаев, 3.И. Тюмасаева [19]) предполагает психологические умения и готовность будущего учителя к гибкому поведению, к осуществлению деятельности в созданных условиях педагогического взаимодействия, а также приспособленность к обстоятельствам и требованиям, при которых следует выполнять конкретные задания в разных местах (спортивный зал, школьный спортивная площадка, бассейн и тому подобное; при условии ограниченности спортивного инвентаря и оборудования).

При реализации принципа адаптации и гибкости планируются и организуются сложные ситуативные задачи, целью которых является формирование и развитие способностей распознавать факторы, которые оптимизируют или блокируют процесс педагогического взаимодействия, развитие умений адекватного поведения и максимального достижения ожидаемых результатов. Считаем, что соблюдение обозначенного принципа требованиям новейшей гуманистической парадигмы в образовательном и профессиональном контексте.

Особенной значимости приобретают также научные принципы профессионального развития и обратной связи. Отметим, что принцип профессионального развития является одним из ключевых факторов планирования и организации образовательного процесса в вузе в условиях современного информационного общества. Он позволяет определить важность непрерывного поиска и обретения современной педагогически релевантной информации, самостоятельного роста, развития профессиональной мобильности, формирование способности будущего учителя физической культуры к осуществлению партнерского сотрудничества. Усматриваем возможность реализации принципа профессионального развития через создание соответствующих педагогических задач, участие в спортивных соревнованиях, участие в учебных проектах и презентациях, проведение круглых столов, дискуссий, мастер-классов, интервью, экспертного опрос и тому подобное.

Принцип обратной связи (С.С. Кашлев [2], Дж. Ричардс [27]) предопределяет проведение рефлексионного анализа относительно выполненной педагогической взаимодействия, рефлексии при выборе технологий или методов решения педагогической задачи; обмен мнениями и впечатлениями о принятых решениях в ходе интерактивного сотрудничества и общения.

Согласно С.С. Кашлеву, обратная связь обнаруживается в реакции на услышанное, прочитанное или увиден- 
ное; предполагает владение информацией (вербального или невербального характера), которую отправляет реципиенту отправитель, демонстрируя при этом степень понимания, доверия к сообщению и согласование с ним [2].

Соглашаясь с зарубежными учеными Дж. Рэнч, В. Ричмонд, Дж. Горхам [31] трактуем понятие «обратная связь» как путь высказывание мнений и впечатлений со стороны студентов к преподавателям и от преподавателей к студентам в интерактивной учебной деятельности. Использование принципа обратной связи помогает решить следующие вопросы: определить уровень достижение указанных результатов; выделить трудности в учебной деятельности и общении студентов, которые препятствуют эффективной реализации взаимодействия на занятии; оценить уровень учебных достижений студентов, не ущерб личности студента.

Учитывая степень важности принципа обратной связи, считаем необходимым освещение таких его функций: оценочная, рефлексионная, мотивационная. Первая помогает педагогу осуществить диагностику целесообразности использования интерактивных методов и дать оценку учебным результатам студентов. Вторая делает возможным осознание педагогом и студентами ценности и корректности обратной связи. Третья предопределяет развитие познавательных способностей и повышения заинтересованности в получении лучших результатов учебной и профессиональной деятельности [31; 28].

Следующим важным принципом является принцип системности. Принцип системности предполагает последовательность и непрерывность овладения интерактивными знаниями, умениями, способностями. Использование этого принципа способствует улучшению процессов логического мышления и запоминания в ходе взаимодействия; развития базовых, ключевых и предметных компетентностей; применение полученных знаний в процессе овладения учебного материала предметов цикла профессионально-ориентированной подготовки.

Принцип целостности предопределяет развитие структурных компонентов педагогического взаимодействия, отражает логическую связь между ними, помогает выделить целостные механизмы его функционирования.

Принцип фасилитации определяет стратегию и тактику управления процессом обучения и означает создание атмосферы доброжелательности и доверия, условий для саморазвития, самосовершенствования личности на принципах гуманизма, полисубъектности, толерантности. Он реализуется через взаимодействие студентов и преподавателя в модели личностно-ориентированной педагогики и гуманистической психологии на основе соуправления, открытости, творчества, наладка контактов для индивидуального совершенствования, личностного роста, раскрытие способностей, познавательных возможностей, стимулирование и освобождение «пластических качеств личности» с помощью субъект-субъектного общения, атмосферы безусловного принятия, понимания и доверия, педагогического внушения и выдвижения оптимистической перспективы. Это дает возможность расширения границ свободы и ответственности участников образовательного процесса в практической деятельности [8].

Физическая культура как часть общей культуры, считает Т.П. Давыдова, «направлена на укрепление и повышение уровня здоровья, всестороннее развитие физических способностей человека и использования их в общественной практике и повседневной жизни» [4]. Соглашаемся, что «физическая культура позволяет с помощью своих специфических методов раскрыть потенциальные возможности человека и выступает как источник формирования разносторонних интересов людей» [4].

По глубокому убеждению Л.И. Лубышева и В.К. Бальсевича, физическую культуру следует рассматривать не только как занятие двигательными упражнениями, процедурами, закалка. Понятие «физическая культура» охватывает более широкий спектр проблем, касающихся режима рационального питания, соблюдения правил гигиены, формирования полезных привычек [11].

Подводя итог, проведенный на основе разной источниковой базы, сравнительный анализ понятия «физическая культура» позволил М.Д. Кудрявцев и др., утверждать о целесообразности его дифференциации [10]. Ученые предлагают рассматривать физическую культуpy:

а) как широкую социальную отрасль, социальную систему, часть общей культуры общества; наиболее общее, объемное понятие, носителем которого является общество;

б) как часть широкой социальной отрасли, воспроизводящей ее функционирование на уровне конкретных объектов: учебно-воспитательных заведений, учреждений, организаций, являющихся ее носителями;

в) как свойство, качество личности (в частности, ученика или студента), как органический компонент личной общей культуры, всестороннего гармоничного развития [10].

Поскольку «физическое воспитание является главным направлением внедрения физической культуры и составляет органическую часть общего воспитания, призванную обеспечивать развитие физических, морально-волевых, умственных способностей и профессионально-прикладных навыков человека», - считают 
ученые М.П. Прохорова и А.А. Семченко, которые таким образом характеризует деятельность будущих учителей физической культуры как субъектов образовательного процесса, осуществляющих физическое воспитание и соответствующую подготовку учащихся и проводят уроки физической культуры [17].

Итак, существенным, и одновременно отличающим деятельность будущего учителя физической культуры является двигательный компонент (необходимость демонстрации физических упражнений, выполнение физических движений вместе с группой, страховка учащихся во время выполнения упражнения), то есть всесторонняя подготовленность учителя по различным видам спорта, предусмотренным школьной программой [3].

Анализируя особенности объекта и предмета труда будущего учителя физической культуры, можно утверждать, что его деятельность - это эмоционально-на- пряженный вид труда высокой интенсивности. С точки зрения коммуникативного подхода, это использование на занятиях физической культурой надлежащего тона и регистра речи, тактичного, личностно-ориентированного, межкультурного общения, применения вербальных и невербальных средств коммуникации, в зависимости от возраста, ситуации, аудитории и тому подобное.

Итак, будущие учителя физической культуры рассматриваются нами как студенты высших учебных заведений, которые направляют свои усилия на получение квалификации в соответствии с определенным сроком обучения и образовательно-квалификационного уровня (например, бакалавры), что позволит им эффективно в дальнейшем осуществлять физическое воспитание школьников. Таким образом, понимание нами понятий современного учителя физической культуры делает возможным определение особенности его интерактивной деятельности.

\section{ЛИТЕРАТУРА}

1. Богданов В.М., Пономарев В.С., Соловов А.В. Информационные технологии обучения в преподавании физической культуры // Теория и практика физической культуры. 2001, №8. С. 55-59.

2. Кашлев С.С. Технология интерактивного обучения. Мн., 2005.

3. Васенков Н.В., Миннибаев Э.Ш. Инновационные методы преподавания физической культуры в вузе // Современные тенденции развития науки и технологий. 2016. №10-7. С. 72-75.

4. Давыдова Т.П. Современные образовательные технологии на занятиях физической культурой // Научное сообщество студентов: междисциплинарные исследования: сб. ст. по мат. XXXV междунар. студ. науч.-практ. конф. № 24(35). URL: https://sibac.info/archive/meghdis/24(35).pdf.

5. Лихачев 0.Е. Интерактивное обучение в физическом воспитании студентов вуза / О.Е. Лихачев, Ю.В. Шиховцов, И.В. Николаева // Здоровье нации: современные ориентиры в физическом воспитании учащейся молодежи: материалы Всероссийской заочной научно-практической конференции, 15 апреля 2013, Самара. С. 44-46.

6. Мокеева Л.А., Шиховцов Ю.В., Николаева И.В. Физическая культура в вузе: интерактивные методы обучения//0lymPlus. Гуманитарная версия. 2015. №1. C. $82-84$

7. Николаев П.П., Николаева И.В. Мониторинг и современные технологии в процессе организации занятий силовым троеборьем в вузе // Теория и практика физической культуры. 2017. №11. С. 89.

8. Качалов Д.В. Концепция формирования целостного педагогического знания у будущих учителей. М. : Академия Естествознания, 2010. 155 с.

9. Бальсевич В.К. Физическая культура для всех и для каждого. М.: ФиС, 1988. 208 с

10. Кудрявцев М.Д., Ситничук С.С., Черепанова А.И., Винников В.Э. Способы использования интерактивной доски на уроках физической культуры. URL: https://www.elibrary.ru/download/elibrary_36824709_93034341.pdf

11. Лубышева Л.И., Бальсевич В.К. Ценности физической культуры в здоровом стиле жизни // Матер. междунар. конф. «Современные исследования в области спортивной науки». СПб.: НИИФК, 1994.

12. Сайкина Е.Г., Фирилёва Ж.Е. Музыкальное обеспечение уроков физкультуры в школе. Повышение мотивации учащихся к занятиям физической культурой и спортом // Технологии образования в области физической культуры: сб. науч.-метод. работ. СПб., 2012.

13. Власова В.П. Физкультурно-оздоровительная деятельность как средство развития социально значимых качеств у будущих учителей физической культуры / В.П. Власова, И.А. Неясова, О.Н. Карабанова // Теория и практика физ. культуры. 2017. №11. С. 18-20.

14. Горшенина С.Н. Содержательные основы формирования технологической компетентности у будущих учителей физической культуры / С.Н. Горшенина, Н.А. Маринкина // Теория и практика физ. культуры. 2017. №1. С. 12-14.

15. Литвиненко С.Н. Конверсия соревновательных технологий в спортизированном физическом воспитании и спорте для всех / С.Н. Литвиненко, Л.И. Лубышева // Теория и практика физ. культуры. 2017. №1. С. 5-7.

16. Евтин А.Б., Гусев А.Н. Использование модульного подхода в реализации прикладной физической подготовки студентов в инженерно-экономическом вузе // Вектор науки Толльятинского университета. №2. 2016.

17. Прохорова М.П., Семченко А.А. Вовлечение обучающихся - будущих педагогов профессионального обучения в проектную деятельность в рамках дисциплины // Вестник Мининского университета. 2018. Том 6. № 2. С.6. 
18. Столяренко Л.Д. Педагогика. Ростов н/Д: Феникс, 2000. 448 с.

19. Челнокова Е.А., Агаев Н.Ф., Тюмасева 3.И. Формирование мотивации студентов к занятиям физической культурой и спортом в высшей школе// Вестник Мининского университета. 2018. Том 6. №1. URL: http://vestnik.mininuniver.ru/jour/article/view/755.

20. Brown D.H. Teaching by Principles. An Interactive Approach to Language Pedagogy. Prentice Hall Regents, 1994. 280 p.

21. Brown S., Attardo S. Understanding Language Structure, Interaction and Variation. The University of Michigan, USA, 2005. 440 p.

22. Di Pietro R.G. Strategic Interaction. Learning Languages through Scenarios. CUP, USA, 1987. 154 p.

23. Diez M.E. Interaction Across the Curriculum: A Model for the Developmentof Competence in Social Interaction. Communication. Education. Division.Cincinnati OH, USA, 1986. $31 \mathrm{p}$.

24. Ellis R. Principles of Instructed Second Language Acquisition. CAL Digest. 2008. 6 p. URL: http://www.cal.org/resources/digest/instructed2ndlang.html

25. Klippel F. Keep Talking. Communicative Fluency Activities for Language Teaching. CUP. UK, 2002. $187 \mathrm{p}$.

26. Moore K.D. Classroom Teaching Skills. 4th ed., McGraw-Hill Inc., USA,1998. 250 p.

27. Richards J.C. Reflective Teaching in Second Language Classroom. CUP, 1994. P. 84-144.

28. Richards J.C., Farrell, T.S.C. Professional Development for Language Teachers. Strategies for Teacher Learning. CUP. UK, 2005. 180 p.

29. Ur P.A Course in Language Teaching Practice and Theory. Cambridge Teacher Training and Development. CUP. UK, 2006. 250 p.

30. Van Lier, L. Interaction in the Language Curriculum: Awareness, Autonomy and Authenticity. Longman. London and New York, 1996. 280 p.

31. Wrench J.S., Richmond V.P., Gorham J. Communication Affect \& Learning in the Classroom. Tapestry Press, MA. USA, 2001. 227 p.

( С Сурков Александр Михайлович (surkov.1954@bk.ru), Карсека Лина Сергеевна (kls-lina@mail.ru),

Гежа Роман Валерьевич (gezha.r@yandex.ru).

Журнал «Современная наука: актуальные проблемы теории и практики»

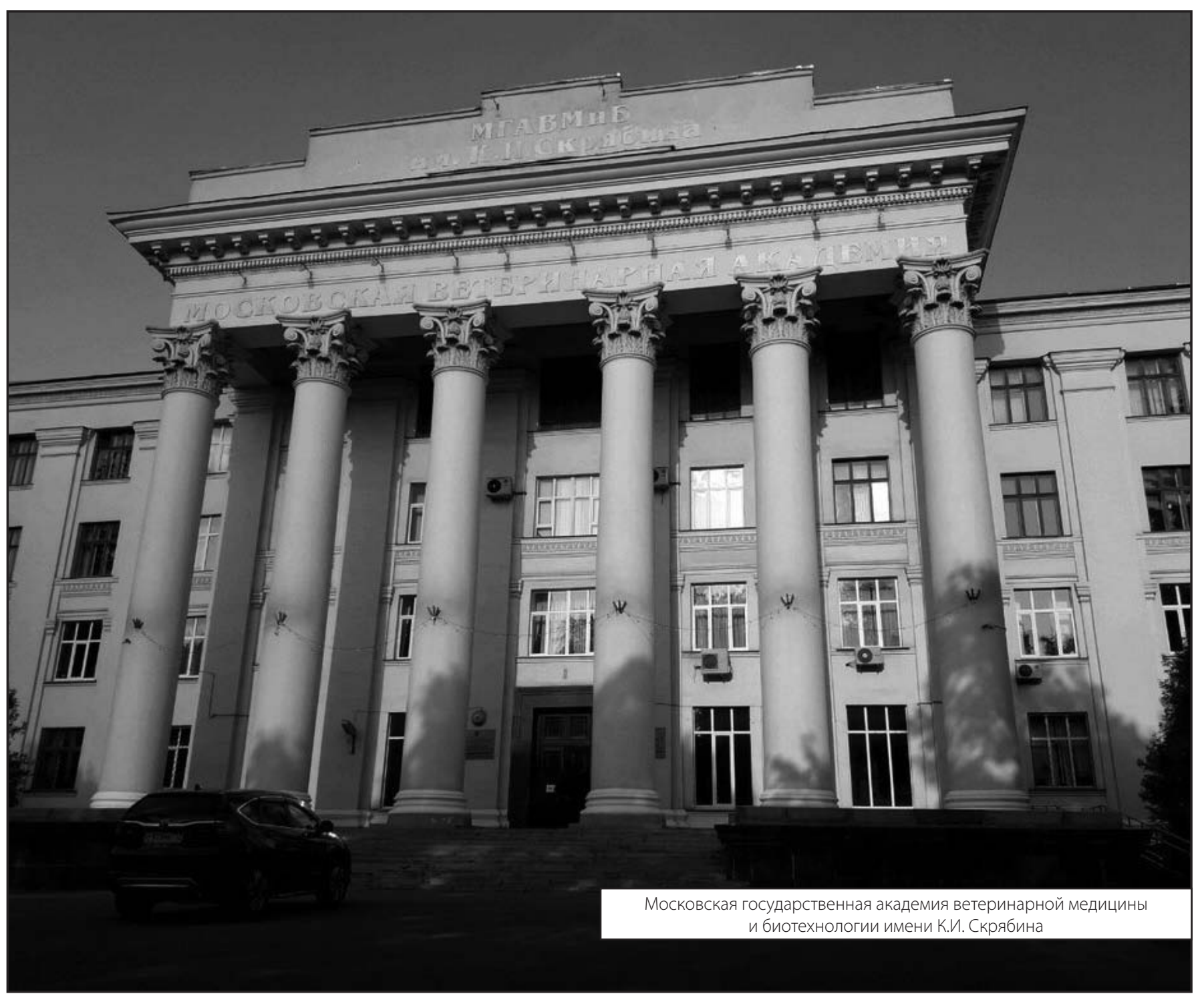

